\title{
Community-Based Adaptation to Climate Change: The Case of a Community University Workshop in Taiwan
}

\author{
Ting-Fang Hsieh and Yuh-Ming Lee *(0) \\ Institute of Natural Resource Management, National Taipei University, New Taipei City 23741, Taiwan; \\ tingfanghsieh@gmail.com \\ * Correspondence: yml@mail.ntpu.edu.tw
}

check for

updates

Citation: Hsieh, T.-F.; Lee, Y.-M. Community-Based Adaptation to Climate Change: The Case of a Community University Workshop in Taiwan. Sustainability 2021, 13, 1729. https://doi.org/10.3390/su13041729

Academic Editor: Ralph Hansmann Received: 30 November 2020

Accepted: 2 February 2021

Published: 5 February 2021

Publisher's Note: MDPI stays neutral with regard to jurisdictional claims in published maps and institutional affiliations.
Abstract: Adaptation to climate change is an important issue now and will continue to be for generations to come. This study designs an educational and practical workshop for adaptation to climate change at a local community level. The community universities in Taiwan normally facilitate social activities and informal learnings. This study thus defines the educational or social activities conducted in community universities as community-based affairs. After reviewing the phase II adaption action plan of Taiwan, critical adaptation sectors of disasters and water resources are identified. A case study on designing the community-based adaptation (CBA) workshop for water resources management in the Dahan River Basin is thereby developed. The learning subjects or practicing topics include an introduction to climate change impacts and their mitigation and adaptation; adaptation sectors of disasters, infrastructure, water resources, and agricultural production; and the utilization of water resources under climate change. Concept mapping of climate change impacts and debating possible global climate trends could further encourage participants to think in-depth and to act accordingly. This study also applies the rigor and relevance (R\&R) framework to assist in the design of the CBA workshop and thereby to assess the effectiveness after its delivery. To further investigate the two-dimensional R\&R levels of the CBA workshop, this study proposes eight combinations of contents and outcomes (tasks). In summary, this workshop gives background knowledge on geography and applies the analysis tool of concept mapping. The 10 learning subjects or practicing topics developed are mostly at the high rigor levels of 4-Analysis and 5-Synthesis. The overall "application level" of the CBA workshop is ranked as level 4 of "predictable real-world application." The eight tasks that can "expand" the rigorousness of knowledge acquisition and "empower" the relevance of skill application are found to fall into Quadrant "C-Assimilation".

Keywords: community-based adaptation (CBA); climate change; the R\&R framework; water resources management

\section{Introduction}

\subsection{Changes in the Climate System and Responses to Be Made}

Climate change is a global issue that will have impacts on the natural environment, economy, and societies. The impacts on the natural environment include changes in the global hydrological cycle, global warming, and, consequently, the intensification of extreme weather events. In particular, extreme precipitation or intensified rainfall, triggering floods and landslides, may destroy residential areas, which could pose a serious threat to societies. Economic impacts include a decrease in agricultural production and threats to human life and property. The social impacts refer to forced changes in lifestyle and therefore the adjustment of public policies and environmental education programs. The Intergovernmental Panel on Climate Change (IPCC), through the publication of its Assessment Report 5 (AR5), addressing the emerging issues of climate change, emphasized the importance of risk management and responsive planning to combat the disasters caused by climate change.

Facing up to the change of the climate system, mitigation and adaptation are two equally important responses in the sustainable development domain. "Mitigation" means 
a reduction in greenhouse gas emissions in various sectors such as industries, commerce, and households. "Adaptation" focuses on reducing the vulnerability (or increasing the resilience) of human and natural systems to the impacts of climate change through adjusting lifestyles or societal structures (Figure 1, adapted from Munasinghe [1]). From the perspectives of the environmental, economic, and social dimensions that boost sustainable development, mitigation mainly applies to economic or technological measures to reduce greenhouse gas emissions. Adaptation, alternatively, is intended to increase the resilience of societies to the damage caused by climate change through social or educational instruments. This study, focusing on the sustainable development domain and particularly the adaptation to climate change, plans to develop an educational tool for local communities to resolve the water resources management issues caused by extreme hydrological events.

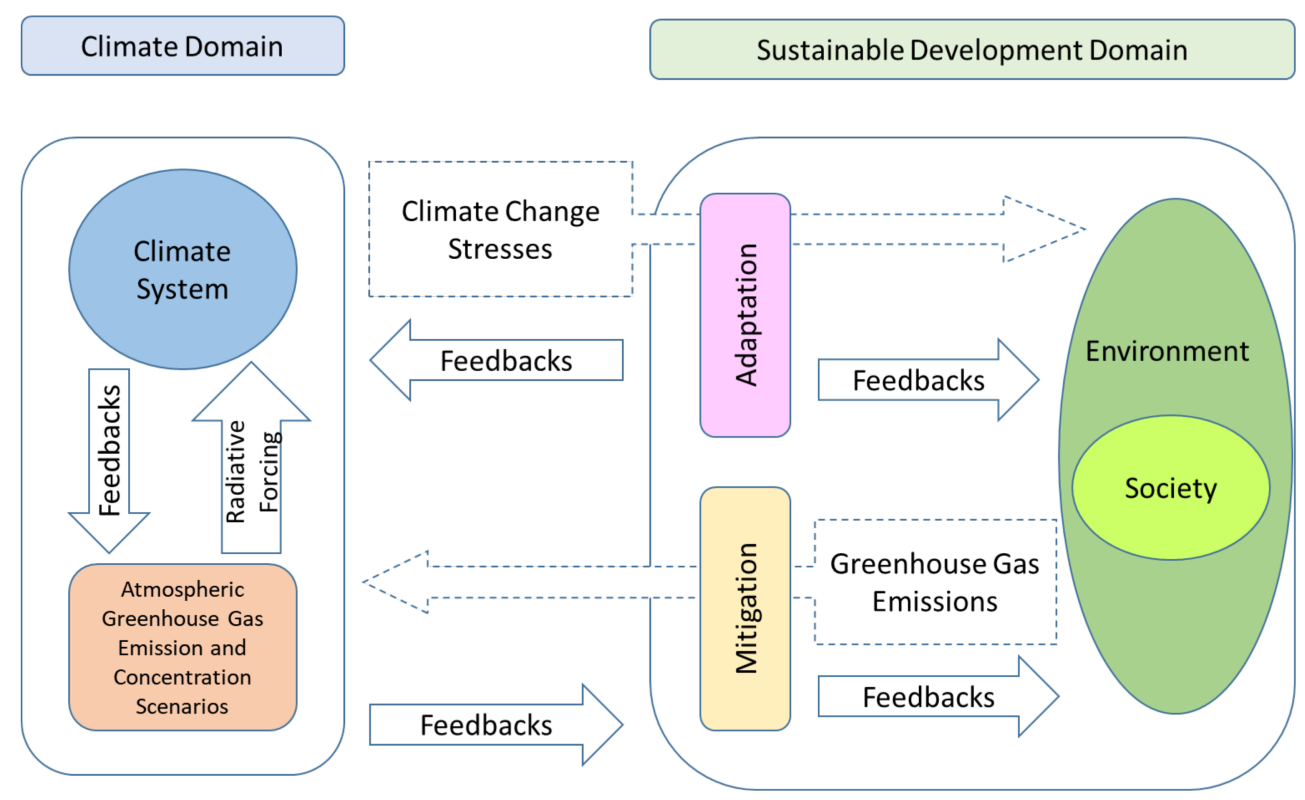

Figure 1. Conceptual framework of mitigation and adaptation (adapted from [1]).

As described by Chang and Hsieh [2], community universities were established with the aims of offering easier access to education and promoting the development of civil society in Taiwan. These non-profit/non-governmental organizations (NPOs/NGOs), providing course programs with focuses on academic, lifestyle, and community activities, have become some structured channels for lifelong education. In other words, differing from the formal higher education institutions for graduates of secondary schools in most countries, community universities in Taiwan are, more or less, social venues for retirees or learning places for outside-of-work (or off-work) activities at a local or community scale. They are more of some community adult education programs in which the community citizens can take courses for personal development and further for community benefits. In addition, community universities in Taiwan normally "sojourn" in secondary schools rather than establish independent institutions. The "informal" educational or social activities conducted in "community universities" can help senior generations to adapt to climate change. This study thus defines the educational or social activities conducted in community universities as community-based affairs. Discussions related to water resources management taking place in community universities can be treated as a focus of community-based adaptation to climate change.

\subsection{Defining Community-Based Adaptation (CBA)}

As defined by Reid et al. (2009) [3], "Community-Based Adaptation (CBA) to climate change" is "a community-led process, based on communities' priorities, needs, knowledge, and capacities, which should empower people to plan for and cope with the impacts 
of climate change." Climate change is a complex issue and subject to collective efforts. Community-based adaptation takes climate-related issues "back to the local." With local communities as the mainstay, not only cultural structures or lifestyles could be consciously rebuilt, but also more stakeholders' inputs could be acquired. Stakeholders' inputs may include ecosystem services for community beneficiaries and consumer groups. The more stakeholders can be engaged, the more "empowerment" can be achieved.

Relevant literature discussing CBA to climate change, for instance, is compiled as follows:

(1) Huq and Reid (2004) argue that community adaptation is community-based and propose the most effective way to manage risks with climate change adaptation as it encourages the community to achieve the goal of sustainable development [4].

(2) Verner (2012) further concludes that all CBA to climate change literature stresses the need for adequate financing. Simple financial services play a critical role and can have a great impact, especially for poor people, allowing them to increase their asset base, widen their economic possibilities, and reduce their vulnerability to climate change. Local governments and municipalities have developed a very low capacity to adapt to climate change [5].

(3) Forsyth (2013) points out that community adaptation is a formal adaptation that aims to reduce the risks of climate change for the world's poorest people [6].

(4) Dodman and Mitlin (2013) argue that community adaptation is based on the premise that local communities have the skills, experience, knowledge, and networks to adapt to local activities, increase environmental tolerance, and reduce the impact of climate change vulnerability [7].

(5) Magee (2013) argues that community-based adaptation to community-based climate change can lead communities to progress based on their strengths, needs, knowledge, and skills. These are sufficient to enable residents to adapt and plan for the effects of climate change. It must make local residents the core of its planning and make plans within the capabilities of the residents [8].

(6) Ensor et al. (2014) point out that a "community" refers to a group of people who have common goals and is generally used to describe those who live in the same village or region. This particular group of people faces challenges together at specific locations and will therefore work together to address these challenges. In the future, in community planning against a changing climate, we must think together about ecosystem services and governance, economy, society, culture, land and resources, health, and infrastructure construction [9].

(7) Uitto et al. (2107) point out that adaptation and mitigation are two different but linked dimensions of social, economic, and environmental sustainability. Adaptation concerns how the social and economic domains are "ready" for change in the environmental domain, and includes the resulting actions. Mitigation focuses on the particular ways society and the economy use natural resources and aims to make these more environmentally sustainable [10].

(8) Morgan (2017) points out that "Community-based adaptation" is receiving growing attention from NGOs, climate change initiatives, and researchers worldwide [11].

\subsection{Workshops Developed in Community Universities to Empower Adaptation to Climate Change}

According to the "Taiwan Adaptation Platform" (TAP) [12], the phase II National Climate Change Adaptation Action Plan (2018-2022) was promulgated in 2018. The action plan was compiled with the aims to "improve national climate change adaptation ability, coordinate disaster prevention, and response strategies, reduce vulnerability, increase resilience and echo the sustainable development goals". The nine assigned sectors to implement action plans are disasters, infrastructure, water resources, land use, coastal and marine environment, energy supply and industry, agricultural production and biodiversity, public health, and capacity building. Among the nine implementing sectors, action plans related to disaster, water resources, land use, energy supply, agricultural production, public 
health, and capacity building could be accomplished through "informal" educational or social activities conducted at community universities. Based on the information gathered from websites maintained by the Taiwan Ministry of Education [13] and the National Association for the Promotion of Community Universities (NAPCU) [14], most of the educational or social activities conducted in community universities are in the form of workshops. In other words, combinations of lectures, discussion, game playing, concept mapping, and essay writing are delivered in workshops at community universities.

The community universities are organized based on the tertiary administrative divisions, townships, or districts. There are about 83 community universities in Taiwan. Again, based on the information compiled from websites maintained by the Taiwan Ministry of Education [13] and the National Association for the Promotion of Community Universities (NAPCU) [14], about 40 community universities offer or conduct workshops related to adaptation to climate change (CBA workshops hereafter). This study further aggregates the CBA workshops delivered in community universities in Taiwan into three categories based on regional characteristics and their corresponding climate issues. They are as follows:

(1) Concerning the adaptation of water resources and agricultural production in Northern Taiwan: mainly issues related to life-supporting systems (food) and economic development (water demand).

(2) Concerning adaptation sectors of land use and energy supply in Central Taiwan: mainly issues related to power generation and scientific park development for the ICT industry.

(3) Concerning adaptation sectors of public health and disaster in Southern Taiwan: mainly issues related to natural disasters (such as flooding, debris flow, and drought) and pollution emitted by heavy industries.

Among the 40 community universities offering CBA workshops, seven communities focus on adaptation sectors of the water resource and agricultural production, and six communities concentrate on the "mitigation and adaptation" of natural disasters. Furthermore, almost all of the communities offering CBA workshops engage in capacity building and consensus forging. That is, even the senior generations are aware of the vulnerability to climate change and are willing to take actions to abate and adapt to the impacts of climate change. This study, taking the adaptation planning of water resources in Northern Taiwan as an example, is intended to construct a development tool for designing a CBA workshop and applies the rigor and relevance (R\&R) framework to assess the effectiveness of the workshop.

\section{Framework for Designing and Assessing the CBA Workshop}

As stated previously, the CBA workshops offered by community universities in Taiwan need to be classified as "informal" and relatively social activities rather than formal curriculums. The topics or contents of those CBA workshops incorporated, such as disaster preparatory planning and water resources management, however, appear to be "educational." This study thus applies a relatively formal tool, specifically the rigor and relevance (R\&R) framework, to assist in the design of a CBA workshop and thereby assess its effectiveness. This section first introduces the general rigor and relevance framework developed by the International Educational Leadership Center [15,16], followed by a description of the CBA workshop design concepts adopted and applied in this study.

\subsection{Rigor and Relevance (RER) Framework}

As described in the "Online Teaching \& Technology Blog" [17], the "Rigor Relevance Framework" (originally the Rigor and Relevance Framework) was developed "to examine curriculum, instruction, and assessment along the two dimensions of higher standards and student achievement." The two dimensions are as follows [17]:

(1) The Knowledge Taxonomy (y-axis), based on Bloom's Taxonomy [18]: Six-level thinking continuum. 
(2) The Application Model ( $x$-axis), developed by Bill Daggett [15]: Five-level knowledge continuum.

The "Rigor and Relevance Handbook" published by the International Educational Leadership Center further describes the two dimensions as follows [19]:

"Rigor" means the rigorousness of the academic program. Students use several learning processes to complete the challenging tasks, such as thinking, analysis, problemsolving, evaluation, and creativity to gradually develop cognitive skills.

"Relevance" means that students must use concepts or skills to solve real-world problems in the learning process. This kind of learning emphasizes the need to combine different domain knowledge and situations. Students solve problems of varying levels of complexity, whether simple or complex.

The two dimensions of the R\&R architecture are "Knowledge Taxonomy" and "Application Model." The knowledge classification comes from the concept of the thinking continuum. The following are the "six levels of thinking" proposed by Benjamin Bloom [15-20]:

(1) awareness/knowledge;

(2) comprehension;

(3) application;

(4) analysis;

(5) synthesis;

(6) evaluation.

The second continuum, created by Willard Daggett, is known as the Application Model. The five levels of this action continuum are as follows [15,16,19,20]:

(1) knowledge in one discipline;

(2) apply within the discipline;

(3) apply across disciplines;

(4) apply to real-world predictable situations;

(5) apply to real-world unpredictable situations.

The rigor and relevance framework has four quadrants $[15,16,19,20]$ :

Quadrant A-Acquisition: Students collect and store all kinds of knowledge and information, in the hope that they will remember or understand the acquired knowledge.

Quadrant B-Application: Students solve problems, design solutions, and complete tasks by applying appropriate knowledge to new and unpredictable situations.

Quadrant C-Assimilation: Students can automatically and naturally apply the knowledge to solve and analyze problems, and conceive unique solutions.

Quadrant D-Adaptation: Students conduct high-level and complex thinking, and use their knowledge and skills to create solutions. When they adopt solutions, they can also give feedback and improve their knowledge and skills.

The dimensions (or models), quadrants, and levels of the rigor and relevance framework are further illustrated in Figure $2[15,16,19,20]$. 


\section{Knowledge}

\section{Taxonomy}

Evaluation
Synthesis
Analysis
Application
Comprehension
Knowledge/
Awareness

6

5

4

3

3

1

Knowledge

in one

discipline

\section{A

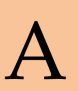

Acquisition

2 discipline

\section{Assimilation}

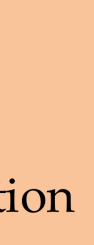

3

Apply

across

disciplines

\section{Application Model}

Figure 2. Dimensions, quadrants, and levels of the rigor and relevance framework $[15,16,19,20]$.

\subsection{Development of the Water Resource CBA Workshop}

To develop a community university CBA workshop for the water resource sector, this section describes the procedures applied. This study defines the spatial scale of the water resource adaptation concerns as a river basin, which is the focal point of the CBA workshop. The first step of the development process is therefore to identify the six rigor levels of thinking of the workshop. As far as the adaptation planning of water resources management in a river basin is concerned, the topics of concern to be covered include (1) knowledge of climate change; (2) community-based adaptation; (3) aspects of the river basin; (4) adaption in the concerned sectors; (5) utilization of water resources; (6) impacts at the national level; and (7) trends of global change. The numbering of the topics, referring to the levels of thinking, are (1) knowledge/awareness; (2) comprehension; (3) application; (4) analysis; (5) synthesis; and (6) evaluation.

The second step of the process is to determine the five relevance levels of application of the workshop. As suggested by the Rigor and Relevance Handbook published by IELC [19], the relevance analysis or "level of application" can be determined by applying a "decision tree." The decision tree, as illustrated in Figure 3, is applied to determine the level of application, i.e., the topic of concern incorporated in a course or a workshop in this study. It is relatively straightforward and basically a "screening" procedure. 


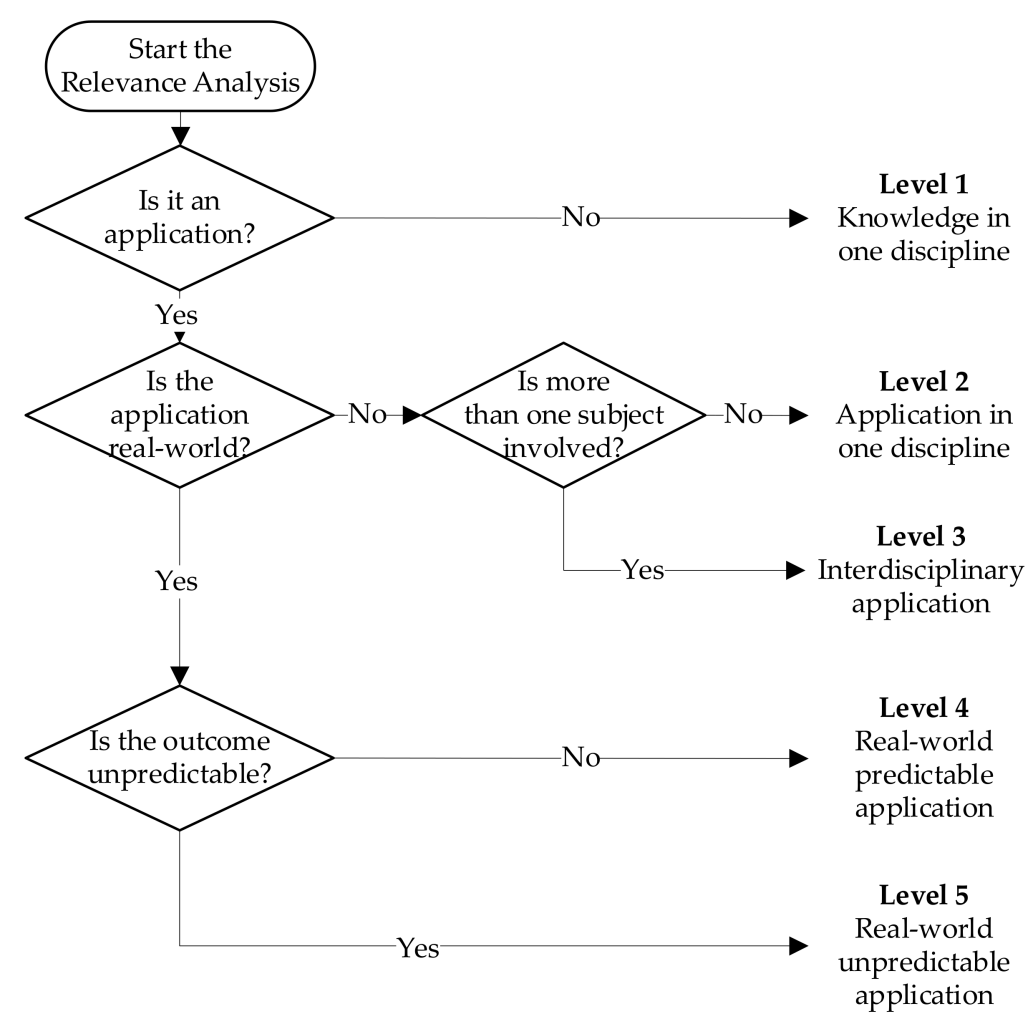

Figure 3. The decision tree of relevance analysis proposed by the rigor and relevance (R\&R) framework [19].

Ultimately, the third step is to aggregate and assess the collective rigor and relevance aspects of the workshop. To pinpoint the R\&R quadrants of the contents incorporated or the outcomes expected of the workshop, a checklist of rigor and relevance aspects can be applied. The checklist, as suggested by the Rigor and Relevance Handbook [19], consists of four sections (corresponding to the four quadrants of the R\&R framework) with four choices of verbs, applications, focuses, and works to be checked, respectively. Detailed descriptions of the checklist applied in this study are presented in the next section.

\section{Designing the CBA Workshop-The Case Study}

As described in Section 1.3, the adaptation sectors of CBA-related workshops offered by community universities in Taiwan mainly focus on water resources, agricultural production, as well as the "mitigation and adaptation" of natural disasters. In particular, water resources management in Northern Taiwan is critical due to its twofold purpose: lifesupporting water supply and life-threatening hydrological hazards. The CBA workshop to be developed, therefore, concentrates on the planning of water resources management in the Dahan River Basin, the largest watershed in Northern Taiwan. A general introduction to the target watershed is presented first. The second subsection reviews, in greater detail, the relevant adaptation sectors and management issues of the watershed. The design of the Dahan watershed CBA workshop concludes the case study.

\subsection{Introduction to the Dahan River Basin}

The Dahan River (a tributary of Tamsui River) is the largest stream in Northern Taiwan. The river is $135 \mathrm{~km}$ long and has a watershed of 1163 square $\mathrm{km}$. The river basin covers most of the vital parts of the Great Taipei Metropolitan Area, within the boundary of three municipalities, Taipei City, New Taipei City, and Taoyuan City. The upstream of the river is also the catchment area of the Shihmen Reservoir, which supplies water demands for agricultural use in Taoyuan City and supplies part of the public demand in the three municipalities. About 8 million people are living here; this means one-third of Taiwan's 
population resides in this basin. Figure 4 illustrates the geography of the river system and the three municipalities comprising the Great Taipei Metropolitan Area.

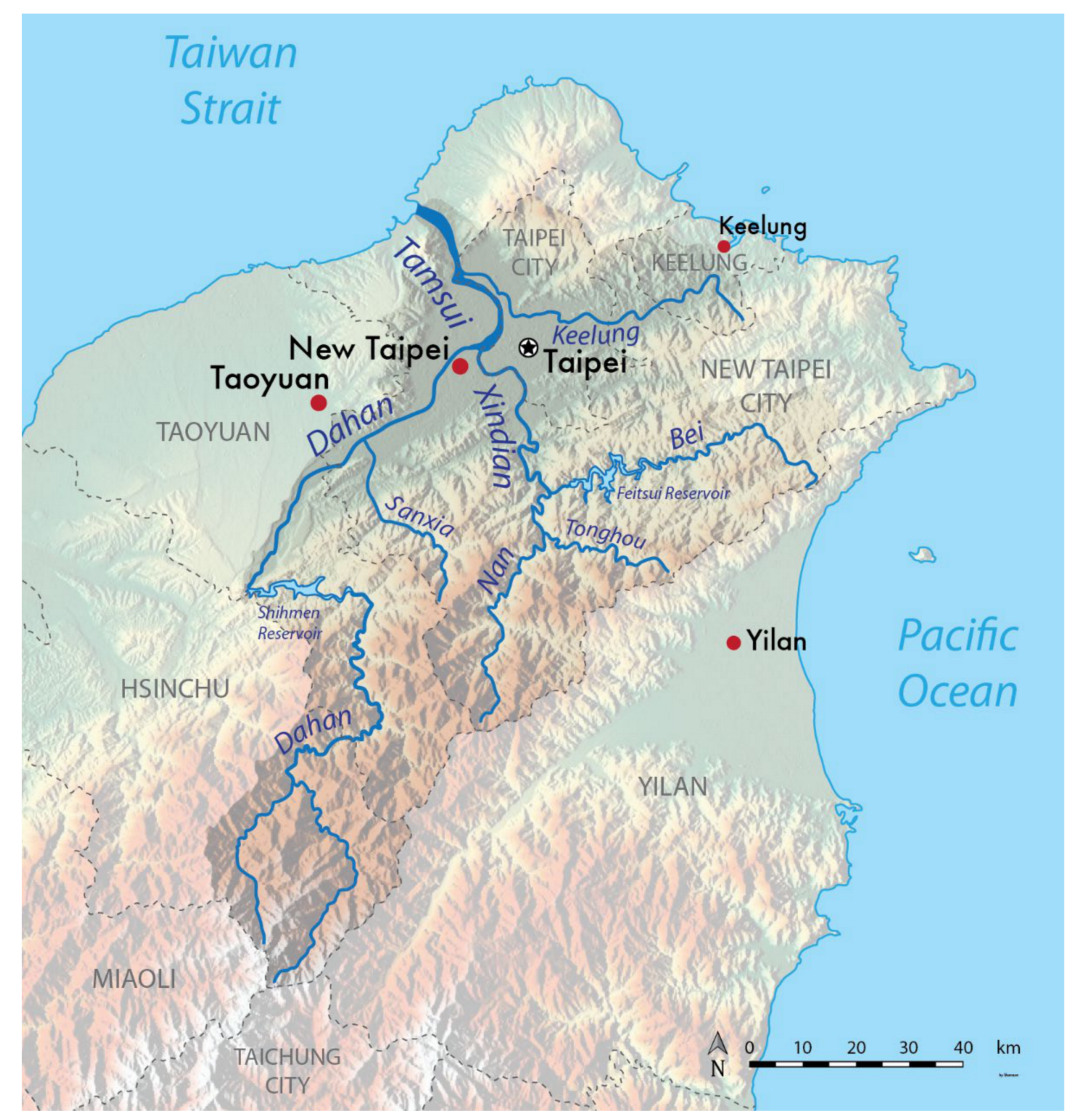

Figure 4. Map showing the Tamsui River (and its tributary, the Dahan River) in Northern Taiwan (https:/ / commons.wikimedia.org/wiki/File:Tamsuirivermap.png (accessed on 2 February 2021); CC-BY-SA-4.0,3.0,2.5,2.0,1.0).

Taking Taiwan's geographical features and social conditions as an example, drastic changes in temperature and rainfall patterns may impose impacts on various adaptation sectors. There are many issues or hazards that have occurred or may occur in the future in the Dahan River Basin, including the following:

(1) Typhoons, bringing in torrential rainfall, may cause floods, soil erosion, and more severe debris flows or landslides;

(2) Subsistence infrastructure may be damaged by the abovementioned disasters;

(3) The utilization and management of water resources becomes more and more difficult;

(4) Hydrologic hazards and malmanagement of water resources may impose threats to food security and loss of biodiversity;

(5) Societal vulnerability and environmental sensitivity may be strengthened by these issues and hazards.

As a result, the management issues affected by climate change that the Dahan River Basin has to face include the following:

(1) Water supply problems in the Greater Taipei Metropolitan Area, such as the management of Shihmen Reservoir; water collection and distribution; and the balance between the public water supply, industrial water demands, and irrigation;

(2) The assurance of food security and public health, such as agricultural production; the conservation of biodiversity; heat island problems; and the control of infectious diseases; 
(3) The planning and implementation of disaster prevention and rescue systems, such as the urban atypical utilization and development; sediment detention pond and flood detention basins; and emergency response planning.

It is thus clear that the CBA workshop for the adaptation preparation and planning of water resources management in the basin should enable communities to realize the urgent issues that need to be resolved and formulate plans of action accordingly.

\subsection{Review of Adaptation Sectors of Concern in the Dahan River Basin}

As stated previously, the phase II "National Climate Change Adaptation Action Plan (2018-2022)" of Taiwan incorporates nine adaptation sectors to implement action plans. This subsection reviews and discusses in greater detail the adaptation sectors relevant to the Dahan River Basin affected by climate change. Due to the special geographical location and social attributes, the possible impacts of climate change in Northern Taiwan need to be analyzed in the light of more scientific evidence to estimate the possibility of changes in temperature and rainfall, such as typhoons and storms, increasing frequency of floods and droughts, the vulnerability of societal communities, the sensitivity of the land, soil erosion, insufficient energy supply, food instability, and the loss of biodiversity, all easily leading to complex disasters. The following are the relevant sectors of adaptation in the Dahan River Basin that this study will address.

\section{(1) Disasters}

Extreme rainfall increases the risk of flooding, which, coupled with northern Taiwan's fragile geological conditions, can easily lead to devastating water-soil complex disasters; and longer droughts will have a severe effect on water-intensive industries, such as semiconductors, and on people's lives. Disasters such as floods, droughts, and landslides will become more serious due to climate change. This not only impacts the resilience of the disaster prevention system but also increases the difference in rainfall periods due to climate change, resulting in more serious droughts and floods and more difficult water scheduling.

\section{(2) Infrastructure}

Climate change not only has a direct impact on personal safety but also affects the various infrastructures that support our lives. The upstream watershed of the Dahan River Basin is the catchment area of the Shihmen Reservoir. Related facilities such as dams, upstream barrages, water purification plants, tap water pipe network systems, water conservancy structures, etc., are critical to the water supply system. Extreme rainfall will put pressure on those water conservancy facilities, and the silt washed away during rainfall will increase water turbidity and reduce the future water supply. In addition, extreme temperatures may cause water pipeline systems to be distorted due to thermal expansion and contraction.

\section{(3) Water Resources}

Climate change has caused the atmospheric temperature to rise, which has also affected the availability of water resources. More and more scientific evidence has shown that rainfall, runoff, and evapotranspiration will increase in Taiwan in the future. Changes in rainfall patterns and distribution have not only impacted hydrological characteristics, river flow, water supply systems, irrigation, and water use but have also increased the risk of complex disasters during high-water periods, as well as drought and river pollution problems during low-water periods. This has not only affected the water quality of rivers but also made it more difficult for the water resources department to adjust its operations.

(4) Agricultural Production and Biodiversity

Agricultural production is a biological industry that is highly dependent on natural resources such as water and soil nutrients. Climate change causes an atmospheric temperature rise and uneven rainfall, which not only disrupts crop growth and affects ecosystems, 
but also affects the yield and quality of agricultural products, endangers food security and productivity, and causes a loss of biodiversity.

\subsection{CBA Workshop: Adaptation to Climate Change in Dahan River Basin}

Based on the abovementioned discussions and arguments, this study takes the adaptation to climate change in the Dahan River Basin as an example to design a CBA workshop. The adaptation sectors of concern are disasters and water resources. The designated venue to host the workshop is San-Ying Community University, sojourning in Sanxia High School in New Taipei City. The subjects or topics to be taught or discussed in the workshop include community-based climate change adaptation education and the introduction of river terrain environment changes in the Dahan River Basin. In addition, some activities to encourage community residents to think in-depth about planned adaptations to water resources and land use, as well as strategies of sustainable development in the Dahan River Basin, are considered.

Referring to the adaptation sectors of concern reviewed in the previous subsection, the learning subjects, visit sites, discussion topics, and objects to be designed in the CBA workshop are as follows.

(1) Disasters: Explore the waterfront space planning site of the Dahan River in the metropolitan area to discuss with local people issues of disaster prevention and rescue and riverside park use so that people who participate can reflect on the relationship between the utilization of waterfront green space and climate change adaptation.

(2) Infrastructure: Through visiting the catchment area of the Pan-Hsin Water Purification Plant, located in New Taipei City, the workshop will explore the relationship between climate change and water resources planning to allow participants to reflect on the water price calculation, water resources costs, and other issues, to cultivate environmental citizenship awareness.

(3) Water Resources: To enhance public awareness of the history of river change and water culture, the workshop could enable participants to value nature and think about how it might coexist with the economy to adapt to climate change. It also can enable participants to change their daily water use habits and advance their sense of environmental responsibility.

(4) Agricultural Production and Biodiversity: The workshop plans to visit organic farms located in water conservation areas around the watershed. Through the practices or experience activities of water cycling, friendly farming, and the food and kitchen waste cycle, the workshop can enable participants to understand the relationship between food safety and the "edible landscape" and henceforth to establish a lowcarbon, sustainable home.

The Sanxia and Yingge Districts (collectively referred to as San-Ying Area) in New Taipei City are located on two sides of the middle reaches of the Dahan River and have a similar geographical environment. Early human ancestors developed settlements across the Dahan River. Due to climate change, community residents may face floods and landslides caused by extreme weather, land use and development, water resources utilization, changes in the agricultural environment, and the pressure on subsistence infrastructure caused by extreme precipitation, so community residents need to face and adjust to these environmental issues. As a result, the CBA workshop for adaptations to climate change in the Dahan River Basin is designed to increase residents' capacity for disaster prevention, mitigation, and adaptation. The workshop is designed to be conducted at San-Ying Community University. The topics to be covered, the types of activities, and the duration of the workshop are listed in Table 1. The topics include an introduction to climate change's impacts and its mitigation and adaptation; adaptation sectors of disasters, infrastructure, agricultural production, and biodiversity; and the utilization of water resources under climate change. In the concluding part of the workshop, concept mapping of climate change impacts on Taiwan's environment and debating possible global climate trends could further encourage participants to think in-depth and to take practical action. The types of activities 
could be lecturing, discussion, site visiting, practicing, debate, and concept mapping, as well as combinations of the above.

Table 1. The community-based adaptation (CBA) workshop for the adaptation to climate change in the Dahan River Basin.

\begin{tabular}{ccc}
\hline Learning Subjects/Practicing Topics & Type of Activities & Hours \\
\hline Mitigation and Adaptation of Climate Change & Lecturing/Discussion & 2 \\
Introduction to Community-Based Adaptation & Lecturing/Discussion & 2 \\
Geographic and Cultural Aspects of the Dahan River Basin & Lecturing/Discussion & 4 \\
Adaptation in the Disaster Sector & Site-Visiting/Debate & 2 \\
Adaptation in the Infrastructure Sector & Site-Visiting/Discussion & 2 \\
Adaptation in the Water Resource Sector & Site-Visiting/Discussion & 2 \\
Adaptation in Agricultural Production and Biodiversity & Site-Visiting/Practicing & 2 \\
Utilization of Water Resources under Climate Change & Discussion/Debate & 2 \\
Impacts of Climate Change on Taiwan's Environment & Concept Mapping/Debate & 2 \\
Debate on Trends of Regional and Global Climate Change & Concept Mapping/Debate & \\
\hline
\end{tabular}

\section{Assessment and Discussion}

Based on the content of the CBA workshop for the adaptation to climate change in the Dahan River Basin presented previously, this section attempts to assess the levels of knowledge and application of the workshop by applying the R\&R framework, followed by a discussion on the implementation of the workshop.

\subsection{Six Levels of Rigor and the Application Level of the Dahan Watershed CBA Workshop}

As listed in Table 1, the CBA workshop incorporates 10 subjects to address adaptation planning in the Dahan River Basin. As the Dahan River and the Shihmen Reservoir form a crucial water system that supplies water for public use (drinking water), industry, and agricultural irrigation, the workshop allocates more time to the subjects of geographic and cultural aspects of the Dahan River basin and adaptations in the water resource sector. After the content is designed, this study applied the R\&R framework to assess the level of thinking (or rigor) of the subject or topic to be imparted. The assessment rule is relatively straightforward. The general introduction to climate change is at the level of knowledge. With the incorporation of stakeholders' engagement, the community-based adaptation needs deeper thinking and should be ranked as comprehension. Advancing further, the exploration of the geographic and cultural aspects of a river basin necessitates an application level of thinking. Adaptation in the concerned sectors requires the capability of analysis or even synthesis. The concluding and inspiring topics, involving some practices of concept mapping and debate, should be classified at the level of synthesis and evaluation. Figure 5 illustrates the assessment results for the rigor dimension of the CBA workshop.

\begin{tabular}{|c|c|}
\hline CBA Workshop - Subject / Topic \\
\hline Mitigation and Adaptation of Climate Change
\end{tabular}

Figure 5. Assessment of the rigor dimension of the CBA workshop subjects or topics. 
The overall "application-level" of the CBA workshop in the relevance dimension can be determined by applying the decision tree depicted in Figure 3. As the workshop deals with adaptations in the water resource sector and is about the real-world application, the decision will not end at levels 1 to 3 . Although there is some uncertainty about global change trends, the outcome (adaptation planning) is hardly unpredictable. The determination procedure terminates at level 4 , predictable real-world application. The decision tree can also be applied to determine the application levels of workshop subjects or topics. For example, the general introduction to climate change is barely at level 1 (knowledge in one discipline). The debate on global change trends, however, should be designated as the top level of real-world unpredictable application.

\subsection{Four Quadrants of the RER Framework Pinpointing the Dahan Watershed CBA Workshop}

As suggested by the Rigor and Relevance Handbook [19], the four quadrants of the $R \& R$ framework or the two-dimensional pinpointing of rigor and relevance of the CBA workshop can be analyzed by a checklist. The checklist suggested by the Rigor and Relevance Handbook [19] comprises checking items of verbs, needs, focuses, practices, and tasks. Taking the verbs as an example, the knowledge taxonomy verbs that can be used are (1) knowledge-recall; (2) comprehension-reword; (3) application-relate; (4) analysis-deduce; (5) synthesis-develop; and (6) evaluation-determine. Since this study tries to apply the checklist to assess the R\&R levels of the contents and outcomes of the CBA workshop, we change the target of "students" to "participants" and replace "teacher" with "conductor." In addition, we extend the "knowledge" and "solution" for classifying the four quadrants of rigor and relevance to "knowledge and skills" as well as "practices and applications."

To further investigate the R\&R levels of the CBA workshop, this study proposes some "thoughtful" combinations of contents and outcomes (or "tasks") to be conducted. For example,

Task 1 . Understanding the causes and impacts of climate change.

Task 2. Uncovering the societal vulnerability to climate change.

Task 3. Making reports on-site visits to facilities related to adaptation.

Task 4. Drawing concept maps to plan for adaptations to climate change.

Task 5. Relating the geographic and hydrologic features of a river basin.

Task 6. Applying tools to delineate the environmental aspects of a river.

Task 7. Arguing about the management of water resources of a watershed.

Task 8. Debating future trends of regional and global climate change.

Based on the above combinations of contents and outcomes, Table 2 illustrates the two-dimensional pinpointing of rigor and relevance of the CBA workshop. The checklist, adopted from the Rigor and Relevance Handbook [19] with items checked, is presented in an orderly manner. Check the matching descriptions to assess the rigor and relevance of the subject, practice, or application, and help users to find the quadrant to which each combination of content and outcome belongs.

Based on the checked items listed in Table 2, it can be concluded that the contents and outcomes of the CBA workshop mostly fall into Quadrant C-Assimilation. This study consequently pinpoints the abovementioned combinations of contents and outcomes in the two-dimensional R\&R space. In general, Tasks 1, 2, and 8 are related to the educational subject of climate change. Tasks 3 and 4 are designed to cope with adaptation planning. Tasks 5-7 are raised to investigate the water resources management in the river basin. As illustrated in Figure 6, the two-dimensional R\&R assessments of the tasks to accomplish the community-based adaptation to climate change can be discussed further. 
Table 2. Checklist for the two-dimensional assessment of the CBA workshop.

\begin{tabular}{cl}
\hline & \multicolumn{1}{c}{ Quadrant A-Acquisition (Low Rigor/Low Relevance) } \\
$\square$ Yes $\square$ No & Use verbs synonymous with recall and understanding. \\
$\square$ Yes $\square$ No & Call for the explanation of knowledge or skill but not the application. \\
$\square$ Yes $\square$ No & Focus is primarily on the conductor. \\
$\square$ Yes $\square$ No & Require all participants to complete the same work, usually at the same time and speed. \\
\hline & Quadrant B-Application (Low Rigor/High Relevance) \\
$\square$ Yes $\square$ No & Use verbs synonymous with recall, understanding, or application. \\
$\square$ Yes $\square$ No & Call for the application of knowledge to real-world problems. \\
$\square$ Yes $\square$ No & Allow participants to work at their own speed. \\
$\square$ Yes $\square$ No & Require all participants to complete the same work. \\
\hline$\square$ Yes $\square$ No & Quadrant C-Assimilation (High Rigor/Low Relevance) \\
$\square$ Yes $\square$ No & Call for the explanation of knowledge or skill, but not the real-world application. \\
$\square$ Yes $\square$ No & Focus primarily on the participants. \\
$\square$ Yes $\square$ No & Require original participant work. \\
\hline & $\quad$ Quadrant D-Adaptation (High Rigor/High Relevance) \\
$\square$ Yes $\square$ No & Use verbs synonymous with analysis, synthesis, or evaluation. \\
$\square$ Yes $\square$ No & Call for the application of knowledge to real-world problems. \\
$\square$ Yes $\square$ No & Require original participant work. \\
$\square$ Yes $\square$ No & Are complex tasks requiring participants to work independently of the conductors. \\
\hline
\end{tabular}

$\begin{aligned} & \text { Knowledge } \\ & \text { Taxonomy }\end{aligned}$
Evaluation
Analysis

\section{Application Model}

Figure 6. Two-dimensional R\&R assessment of the Dahan watershed CBA workshop.

For those workshop tasks related to the subject of climate change, Task 1 calls for fundamental knowledge of climate change and can be located in Quadrant A-Acquisition, with low rigor and low relevance. "Task 2 . Uncovering vulnerability," evolving from Task 1 (denoted with an arrow from Task 1), needs more advanced knowledge of climate change yet few application skills. We thus can locate "Task 2 . Uncovering the societal vulnerability to climate change" in Quadrant C-Assimilation. Regarding Task 8, the debate on climate change in various scales not only calls for a thorough synthesis of knowledge related to climate change but also involves practices of debating and concept mapping. "Task 8 . 
Debating on future trends of regional and global climate change" should be classified as highly rigorous and relevant, in Quadrant D-Adaptation.

Concerning the tasks for assessing water resources management in a river basin, "Task 5. Relating the geographic and hydrologic features" (more rigorous-Quadrant C) and "Task 6. Applying tools to delineate environmental aspects" (more relevant-Quadrant B) should be conducted interactively (denoted as a double arrow). "Task 7. Arguing the management of water resources of a watershed" similarly needs both a thorough synthesis of knowledge related to water resources adaptation and relevant skills. This task ought to be located in Quadrant D-Adaptation. The practice-oriented tasks of "Task 3. Essaying reports of site-visits to related facilities for adaptation" and "Task 4. Drawing concept maps to plan for adaptation to climate change," aligning with a reasonable degree of rigor and relevance, remain in Quadrants B and C. The two tasks coping with adaptation planning are similarly designed to be conducted interactively and are denoted with a double arrow.

In the $R \& R$ framework, the contents incorporated and the outcomes expected can be allocated into the four quadrants as follows.

\section{Quadrant A-Acquisition}

Refers to a basic understanding of knowledge, and simple recall—for example, understanding the causes and impacts of climate change. That is, the participants collect and store a variety of knowledge and information, and to some extent remember or understand the knowledge gained.

\section{Quadrant B-Application}

Participants can delineate environmental aspects of the Dahan River and will use the acquired knowledge to solve problems. The highest level of the application referred to here is the application of appropriate knowledge to new and unpredictable situations. For example, participants can propose specific solutions to effectively resolve disputes over water resources.

\section{Quadrant C-Assimilation}

The knowledge that participants extend and refine can be naturally applied to relate to interdisciplinary knowledge and thereby used to synthesize aggregated solutions. For example, participants can draft adaptation planning or assess societal vulnerability to climate change.

\section{Quadrant D-Adaptation}

For the complex climate problems in the Dahan River Basin, and even extending to the regional and global scale, a wide range of knowledge and skills can be used to create solutions, and knowledge and skills can evolve after feedback analysis. For example, participants can engage in discussions and debates on future climate trends or appraisals of water resources management strategies.

To sum up, this CBA adaptation workshop is designed with considerations of educational subjects and application topics derived from the individual dimension of the $R \& R$ framework in the first place. This workshop thus requires background knowledge of geography and applies the analysis tool of concept mapping to practical activities. Through facilitating "co-learning" between conductors and participants, students at the community university are encouraged to learn in different disciplines and help each other achieve higher relevance in the field of concern. The 10 learning subjects developed are mostly at the high rigor levels of 4-Analysis and 5-Synthesis. The overall "application-level" of the CBA workshop ought to be ranked as level 4, "predictable real-world application." In the two-dimensional R\&R framework, combinations of contents and outcomes (tasks) need to be proposed. In other words, in terms of rigor, the pursuit of learning is the acquisition of knowledge and the process of organizing knowledge innovation through sharing and expansion. Furthermore, through relating and debating, students can be empowered. The eight tasks of the CBA workshop mostly fall into Quadrant C-Assimilation. 


\section{Conclusions}

In addition to reducing greenhouse gas emissions, social patterns are urgently needed to be restructured to adapt to climate change through adjusting life patterns and enhancing the resilience of humankind. Community adjustment is based on local-scale considerations, with adaptations put forward to reduce the risks of climate change. Due to its complex geophysical conditions, Taiwan has long been categorized as a multi-hazard country. Adaptation to climate change is an important issue for residents now and in generations to come. This study is thus intended to develop an educational and practical workshop on adaptation to climate change at a local community level. The community universities in Taiwan are normally social venues for retirees or learning places for outside-of-work activities. The informal educational or social activities conducted at community universities can play an important role in community citizens' adaptation to climate change. This study thus defines the educational or social activities conducted in community universities as community-based affairs.

To develop a Community-Based Adaptation workshop, this study reviews the phase II National Climate Change Adaptation Action Plan (2018-2022) and summarizes that disasters, infrastructure, water resources, and agricultural production are the four critical adaptation sectors. This study also defines the spatial scale of water resource adaptation concerns as a river basin. A case study designing a CBA workshop for water resources management in the largest river basin in Northern Taiwan is thereby developed. Learning subjects related to climate change, geography, and hydrology; as well as activities to encourage community residents to think in-depth about adaptations to water resources and land use in the Dahan River Basin are incorporated in the workshop. The topics include an introduction to climate change impacts and their mitigation and adaptation; the adaptation sectors of disasters, infrastructure, and agricultural production; and the utilization of water resources under climate change. In the concluding parts of the workshop, concept mapping of climate change impacts on Taiwan's environment and debating possible global climate trends could further encourage participants to think in-depth and take practical action. The type of activities can be lectures, group discussions, site visits, practical work, debates, and concept mapping, as well as combinations of the above.

Although the CBA workshop to be conducted at San-Ying Community University can be classified as an informal social activity, the content appears to be educational. This study thus applies a relatively formal tool of the rigor and relevance $(R \& R)$ framework to assist in the design of the CBA workshop and assess its effectiveness afterward. To further investigate the two-dimensional $R \& R$ levels of the CBA workshop, this study proposes eight combinations of contents and outcomes (tasks). In summary, this CBA workshop is designed with considerations of educational subjects and application topics derived from the individual dimension of the R\&R framework in the first place. This workshop thus requires background knowledge of geography and applies the analysis tool of concept mapping to practical activities. The 10 learning subjects or practical topics developed are mostly at the high rigor levels of 4-Analysis and 5-Synthesis. The overall application level of the CBA workshop is ranked as level 4, "predictable real-world application". The eight contents and outcomes (tasks), which can expand the rigorousness of knowledge acquisition and empower the application of relevant skills, fall into Quadrant C-Assimilation.

In general, adaptation to climate change is highly sensitive to local conditions. This study designed a workshop for the adaptation planning of water resources management in the Dahan River Basin. Besides the focal point of a watershed and the concerned sector of water resource management, there are more sustainability issues and adaptation sectors to be considered. This study thus suggests that more educational and practical workshops can be designed and implemented in other community universities to accomplish "community empowerment". The sustainability issues could cover the three dimensions of sustainable development, such as water conservation, edible landscape, and stakeholders' engagement. The adaptation sectors to be considered could be, for example, land use planning, disaster prevention, and especially capacity building. 
Author Contributions: Writing-original draft preparation, T.-F.H.; writing-review and editing, T.-F.H. and Y.-M.L.; visualization, revision, and supervision, Y.-M.L. All authors have read and agreed to the published version of the manuscript.

Funding: This research and the APC was funded in part by Taiwan Ministry of Science and Technology under the grant number of MOST109-2621-M-305-001.

Institutional Review Board Statement: Not applicable.

Informed Consent Statement: Not applicable.

Acknowledgments: The authors would like to acknowledge that this study adapts some early works conducted in the project of "Study on the framework of Rigor and Relevance (R\&R) and Implementation of the related training workshop". The project was financially supported by the Taiwan Environmental Protection Administration under grant number EPA-102-E102-02-228 with a project duration of December 2013 to September 2014. We would also like to express our gratitude to Jim Warford, an expert from International Center for Leadership in Education (ICLE), for providing on-site instruction and a discussion forum about the R\&R Framework in May 2014.

Conflicts of Interest: The authors declare no conflict of interest.

\section{References}

1. Munasinghe, M. Global Analytical Applications. In Sustainability in the Twenty-First Century: Applying Sustainomics to Implement the Sustainable Development Goals; Cambridge University Press: Cambridge, UK, 2019.

2. Chang, T.Y.; Hsieh, J.J. The Development of Community Universities in Taiwan and Their Roles in Social Capital Accumulation. In Proceedings of the Fourth Annual Conference in Political Economy, International Initiative for Promoting Political Economy, The Hague, The Netherlands, 9-11 July 2013; Available online: http:/ /iippe.org/wp-content/uploads/2013/06/communityuniversity-and-social-capitalTe-Yung-Chang-Taiwan.pdf (accessed on 31 January 2021).

3. Reid, H.; Canon, T.; Berger, R.; Alam, M.; Milligan, A. Community-based Adaptation to Climate Change: An Overview. In Community-based Adaptation to Climate Change; Participatory Learning and Action (PLA) Series, 60; International Institute for Environment and Development (IIED); Russell Press: Nottingham, UK, 2009.

4. Huq, S.; Reid, H. Mainstreaming Adaptation in Development. Inst. Develop. Stud. Bull. 2004, 35, 15-21. [CrossRef]

5. Verner, D. Adaptation to a Changing Climate in the Arab Countries: A Case for Adaptation Governance and Leadership in Building Climate Resilience; MENA Development Report; World Bank: Washington, DC, USA, 2012.

6. Forsyth, T. Community-based Adaptation: A Review of Past and Future Challenges. Wiley Interdiscip. Rev. Clim. Change 2013, 45, 439-446. [CrossRef]

7. Dodman, D.; Mitlin, D. Challenges for Community-Based Adaptation: Discovering the Potential for Transformation. J. Int. Develop. 2013, 25, 640-659. [CrossRef]

8. Magee, T. A Field Guide to Community Based Adaptation; Earthscan-Routledge: New York, NY, USA, 2013.

9. Ensor, J. Emerging Lessons for Community-based Adaptation. In Community-based Adaptation to Climate Change: Emerging Lessons; Ensor, J., Berger, R., Huq, S., Eds.; Practical Action Publishing: Rugby, UK, 2014.

10. Uitto, J.I.; Puri, J.; van den Berg, R.D. Introduction. In Evaluating Climate Change Action for Sustainable Development; Springer: Cham, Switzerland, 2017.

11. Morgan, E.A. The Challenges and Opportunities for Higher Education Institutions at the Science-Policy Interface. In Climate Change Research at Universities_Addressing the Mitigation and Adaptation Challenges; Leal Filho, W., Ed.; Springer: Cham, Switzerland, 2017.

12. Environmental Protection Administration. Taiwan Adaptation Platform, TAP. Available online: https://adapt.epa.gov.tw/eng/ index_en.html (accessed on 30 December 2020).

13. Ministry of Education. Information Web-Site for Community universities in Taiwan. Available online: https://ewncu.moe.edu. tw / Default.aspx (accessed on 30 December 2020).

14. National Association for the Promotion of Community Universities (NAPCU). Localization, Participation, and Adaptation to Climate Change. Available online: https:/ / sites.google.com/a/napcu.org.tw/twcba/dong-tai-shi-jian (accessed on 30 December 2020).

15. International Center for Leadership in Education (ICLE). Using the Rigor/Relevance Framework for Planning and Instruction; ICLE: New York, NY, USA, 2005.

16. International Center for Leadership in Education (ICLE). Rigor and Relevance Framework; ICLE: New York, NY, USA, 2010.

17. Center for Online Learning, Research and Service. Online Teaching \& Technology Blog-The Rigor Relevance Framework. Available online: https://blogs.uis.edu/colrs/2018/01/12/the-rigor-relevance-framework/ (accessed on 30 December 2020).

18. Anderson, L.W.; Krathwohl, D.R.; Bloom, B.S. (Eds.) . A Taxonomy for Learning, Teaching, and Assessing: A Revision of Bloom's Taxonomy of Educational Objectives; Longman: New York, NY, USA, 2001. 
19. International Center for Leadership in Education (ICLE). Rigor and Relevance Handbook, 2nd ed.; ICLE: New York, NY, USA, 2010.

20. International Center for Leadership in Education (ICLE). A Handbook for Teachers-Using Rigor and Relevance to Create Effective Instruction, 3rd ed.; ICLE: New York, NY, USA, 2012. 